\title{
ANALISIS BERAT JENIS DAN OSMOLALITAS URIN SELAMA SUPLEMENTASI LARUTAN ELEKTROLIT PADA PEKERJA DENGAN PAJANAN PANAS
}

\author{
Daru Lestantyo ${ }^{1}$, Suroto $^{2}$ \\ 1,2Fakultas Kesehatan Masyarakat Universitas Dipanegara \\ Email:_daru71@gmail.com, suroto_pd@gmail.com
}

DOI : $\underline{10.24252 / \text { kesehatan.v11i2.6267 }}$

\begin{abstract}
Abstrak
Latar Belakang. Suhu tinggi dapat menjadi pemicu kelelahan tenaga kerja selain akibat postur kerja statis. Pada sistem organ, pajanan panas dapat berdampak pada fungsi ginjal dan keseimbangan cairan. Penelitian ini bertujuan untuk menganalisis dampak pajanan panas pada berat jenis urin dan osmolalitas. Metode penelitian. Penelitian ini memiliki desain eksperimen dengan double blind. Responden dipilih secara purposif dari sejumlah 90 pekerja. Intervensi dilakukan dengan memberikan larutan elektrolit hipotonik dan isotonik. Pemberian larutan elektrolit dilakukan selama jam kerja secara ad libitum. Pengambilan sampel urin dilakukan dua kali yaitu pukul 10.00 dan 15.00. Hasil. Pengukuran sampel menunjukkan adanya low consuming water setelah 4 jam bekerja. Rata-rata konsumsi cairan sebanyak $400 \mathrm{ml}-1100 \mathrm{ml}$ selama 4 jam. Analisis statistik dengan Mann-whitney menunjukkan bahwa tidak ada perbedaan signifikan antar dua kelompok perlakuan $(U=608,00$, and $p$ value 0,954$)$. Sebagian besar responden berada dalam keadaan hypohydrated state ( BJ urin 1,026 ). Simpulan. Sebagian besar responden berada dalam keadaan dehidrasi yang tidak disadari (involuntary dehydration). Kondisi ini memiliki risiko terhadap kecelakaan kerja akibat pajanan panas. Kondisi ini juga disebabkan tidak terpenuhinya penggantian cairan dari larutan elektrolit yang disediakan
\end{abstract}

\section{Kata kunci : Pajanan Panas; Berat Jenis Urin; Osmolalitas; Dehidrasi}

\begin{abstract}
Background. Heat exposure in workplace is one of potential hazard that could harmed to workers especially for their urinary tract system. This study examined the effects of electrolyte water solution in laundry worker's urinary density and osmolality in heat stress environment. Methods. Wet bulb globe temperature, and relative humidity were measured. Seventy workers divided in two groups of thirty five were given isotonic and hypotonic electrolyte solution ad libitum respectively. Fluid intake during working and breaktime were measured. Two samples of urine were taken from each worker at 10 am and $15 \mathrm{pm}$ of working. At the end of study the amount of water consumed were observed. Result. Low consuming water was found after study at average $400 \mathrm{ml}-1100 \mathrm{ml} / 4$ working hour. There was no significant differences in urinary density between the groups $(U=608,00$, and $p$ value 0,954$)$. However, a majority of workers were coming to work in a moderately hypohydrated state (average urinary density 1.026). Conclusions. This study found that "involuntary dehydration" occured in laundry workers, which has implications for heat stress standards that do not make provision for full fluid replacement during heat exposure.
\end{abstract}


Keywords : Heat Exposure; Electrolyte Solution; Urinary Osmolality; Urinary Density;
Laundry Worker

\section{PENDAHULUAN}

Sesuai Peraturan Menteri Tenaga Kerja No 5 tahun 2018 tentang Faktor Fisik di Tempat Kerja telah ditetapkan Nilai Ambang Batas (NAB) suhu di tempat kerja. Penetapan NAB ini dengan maksud untuk memberikan batasan tingkat keselamatan dan kesehatan kerja melalui efek lingkungan fisik yang senyaman mungkin. Pekerja yang masih berada dalam suhu nyaman diharapkan dapat bekerja dengan produktif dan terhindar dari gangguan kesehatan. Penelitian yang dilakukan pada pekerja laundry membuktikan bahwa kerja statis dan lingkungan panas dapat menyebabkan kelelahan yang ditandai dengan pemanjangan reaksi cahaya. Suhu tinggi dapat menjadi pemicu kelelahan tenaga kerja selain akibat postur kerja statis. Penelitian yang dilakukan di Jawa Barat pada pekerja pabrik billet baja menemukan adanya korelasi suhu lingkungan dengan kenaikan suhu inti tubuh. Penelitian Karina, dkk pada pekerja pengecoran baja menemukan rerata suhu dalam ruang $30^{\circ} \mathrm{C}-33^{\circ} \mathrm{C}$ (ISBB). selama 4 jam bekerja. Meskipun angka kecukupan cairan telah ditetapkan dalam AKG (Angka Kecukupan Gizi) tahun 2016 namun secara khusus belum didapatkan angka untuk kecukupan mineral $(\mathrm{Na}, \mathrm{K}, \mathrm{Cl})$ dalam air minum bagi masyarakat Indonesia Kecukupan air minum dan elektrolit juga diperlukan pada masyarakat pekerja dengan paparan suhu lingkungan kerja tinggi untuk menentukan batas aman bekerja agar terhindar dari penyakit dan kecelakaan kerja.

Salah satu potensi bahaya panas pada pekerja adalah pengolahan cucian dengan metode laundry/dry cleaning. Proses kerja maupun alat/mesin yang dipakai memiliki potensi paparan panas yang besar. Kondisi lingkungan ini masih ditunjang oleh layout ruangan tanpa pengatur suhu atau kurang berfungsi sehingga dapat meningkatkan suhu ruang kerja. Pengukuran pada observasi awal penelitian bulan Februari tahun 2018 didapat suhu lingkungan kerja seorang pekerja minum air sebanyak 2-3 gelas ( 400-600 ml ) diluar air yang diminum saat makan siang.

\section{METODE PENELITIAN}

Penelitian secara eksperimental randomized controlled trial secara double blind. Dalam penelitian subjek diberi perlakuan pemberian larutan elektrolit selama 8 jam bekerja. Akan diamati perbedaan pada BJ dan osmolalitas urin pada kelompok perlakuan dan pembanding melalui pemberian suplementasi larutan elektrolit selama 8 jam bekerja. Populasi terjangkau adalah pekerja laundry sebanyak 90 orang. Sampel dipilih secara purposive sampling dengan menggunakan kriteria inklusi, sebagai berikut:

a. Usia 20-40 tahun

b. Bekerja pada tempat dengan paparan panas ISBB $>30^{\circ} \mathrm{C}$

c. Bersedia menjadi responden (informed consent) 
d. Konsumsi $\mathrm{NaCl}$ 2400-2500 mg/hari

e. Tidak memiliki riwayat penyakit saluran kemih

f. Tidak memiliki riwayat penyakit hipertensi

Hasil seleksi secara purposif didapatkan 70 orang partisipan. Suhu lingkungan kerja diukur dengan menggunakan digital Questtemp Heat Area Monitor. Asupan $\mathrm{NaCl}$ dalam makanan menggunakan kuesioner recall $3 \times 24$ jam dan dianalisis dengan Food Processor 2. Status gizi diukur dengan menggunakan Indeks Massa Tubuh ( IMT ) merujuk klasifikasi Kementerian Kesehatan RI. Berat Jenis urin diukur dengan menggunakan Urinometer. Komposisi larutan suplementasi yang diberikan adalah :

1. Larutan elektrolit isotonik, berisi $0,9 \mathrm{~g}$ natrium klorida dan $0,6 \mathrm{~g}$ Potassium klorida per $1 \mathrm{~L}$

2. Larutan elektrolit hipotonik sebagai placebo yang mengandung natrium klorida 0,52 $\mathrm{g}$ dan potassium klorida $0,30 \mathrm{~g}$ per $1 \mathrm{~L}$

Larutan percobaan dikerjakan oleh Bagian Farmasi Fakultas Kedokteran Universitas Diponegoro. Analisis Statistik dengan uji beda secara non parametrik (Mann- Whitney) untuk berat jenis dan osmolalitas urin pada kelompok perlakuan dan pembanding.

\section{HASIL DAN PEMBAHASAN}

\section{a. Suhu Lingkungan Kerja}

Pengukuran dengan Questtemp pada 3 titik pengukuran sebanyak dua kali yaitu pukul 10.00 dan 15.00. Penentuan titik pengukuran dilakukan dengan pertimbangan lokasi sumber panas dan posisi pekerja. Waktu pengukuran dipilih saat pelaksanaan pekerjaan telah memasuki pertengahan waktu kerja ( 2 jam pertama) dan menjelang pulang. Sebelum dilakukan pengukuran, pemetaan ruangan merupakan data dasar dalam menentukan lokasi/titik kegiatan.

Tabel 1. Hasil Pengukuran Suhu Kerja di Ruang produksi

\begin{tabular}{|c|c|c|c|c|}
\hline \multirow[t]{2}{*}{ Lokasi } & \multicolumn{2}{|c|}{ Rerata $\operatorname{ISBB}\left({ }^{0} \mathrm{C}\right)$} & \multicolumn{2}{|l|}{ Rerata } \\
\hline & Jam 10 & Jam 15 & Jam 10 & Jam 15 \\
\hline 1 & 30,3 & 31,1 & 74,4 & 74,8 \\
\hline 2 & 30,5 & 33,3 & 73,8 & 74,3 \\
\hline 3 & 30,1 & 32,2 & 74,5 & 74,6 \\
\hline
\end{tabular}

Menurut Per Menaker No 5/2018 dengan beban kerja sedang, suhu lingkungan kerja telah melebihi Nilai Ambang Batas (NAB) yang diperkenankan yaitu sebesar $26,7^{\circ} \mathrm{C}$. Namun hasil ini masih lebih rendah bila dibanding penelitian Brake, dkk pada pekerja pertambangan dengan suhu lingkungan kerja yang lebih tinggi yaitu $30,7^{\circ} \mathrm{C}$ hingga $35,2^{\circ} \mathrm{C}$. Sedangkan penelitian lain di Australia pada pekerja pertambangan 
menunjukkan hasil 29,50 C suhu kering (dry bulb). Kedua penelitian ini menunjukkan diperlukannya pengaturan suhu di tempat kerja agar tidak melebihi Nilai Ambang Batas (NAB).

\section{b. Usia Responden}

Responden yang diteliti diambil yang berusia antara 20-40 tahun. Pemilihan rentang usia ini berdasar hipotesis bahwa usia produktif memiliki daya adaptasi terhadap suhu tinggi yang masih baik.

Tabel 2 . Distribusi Frekuensi Pekerja menurut Umur

\begin{tabular}{cccc}
\hline No & Kelompok Umur & Frekuensi & Persen \\
\hline 1. & $20-25$ tahun & 18 & 25,7 \\
\hline 2. & $26-30$ tahun & 22 & 31,4 \\
\hline 3. & $31-35$ tahun & 20 & 28,5 \\
\hline 4. & $36-40$ tahun & 10 & 14,2 \\
\hline & Jumlah & 70 & 100 \\
\hline
\end{tabular}

Usia memiliki peranan dalam status kesehatan individu. Terutama apabila seseorang berada dalam paparan potensi bahaya yang kontinu di tempat kerja. Meskipun tidak spesifik, penelitian membuktikan adanya korelasi umur dengan episode serangan heat exhaustion pada pekerja tambang. Pekerja dengan umur di atas 40 tahun relatif lebih rentan terhadap serangan heat exhaustion. Secara fisiologis, faktor usia berhubungan dengan kemampuan ginjal dalam mengekskresikan sisa metabolit untuk mempertahankan keseimbangan biokimia asam basa darah. Semakin bertambah usia seseorang maupun adanya gangguan pada ginjal akan menurunkan fungsi glomerulus dan tubulus dalam pembentukan urin. Pola hidup tidak sehat seperti kurang aktivitas fisik, konsumsi obat dalam jangka lama serta kebiasaan kurang minum dapat pula merupakan faktor pemicu.

\section{c. Indeks Massa Tubuh (IMT)}

Pengukuran Indeks Massa Tubuh dilakukan untuk mengetahui status gizi secara antropometrik guna mengidentifikasi kemungkinan gangguan gizi pekerja baik akibat asupan makanan maupun lingkungan kerja. Berbagai referensi menunjukkan bahwa IMT memiliki pengaruh terhadap kemampuan fisiologis tubuh dalam beradaptasi terhadap panas. Pekerja dengan kemampuan adaptasi panas yang rendah akan berisiko terhadap penyakit dan kecelakaan kerja panas.

Tabel 3. Distribusi Frekuensi Indeks Massa Tubuh Pekerja

\begin{tabular}{cccc}
\hline No & IMT & Frekuensi & Persen \\
\hline 1 & Normal & 65 & $92,84 \%$ \\
\hline 2 & Kelebihan Berat Badan & 5 & $7,16 \%$ \\
\hline & Jumlah & 70 & $100 \%$ \\
\hline
\end{tabular}


Pengukuran IMT diterapkan untuk memperkirakan kemampuan adaptasi individu terhadap suhu tinggi. Selain itu pemantauan berat badan bermanfaat untuk mengetahui adanya penurunan berat akibat dehidrasi. Studi pada 51 orang pekerja di California pada pertengahan musim panas didapatkan penurunan berat badan sebesar 2,3 Kg per hari . Berat badan berlebih yang diikuti dengan penumpukan jaringan lemak menyebabkan tubuh akan memproduksi panas lebih besar. Hal ini kurang menguntungkan bagi pekerja yang berada dalam suhu lingkungan tinggi. Daya adaptasi panas akan rendah sehingga pekerja akan lebih cepat merasa lelah dibanding individu dengan IMT normal.

\section{d. Masa Kerja Responden}

Tabel 3 .Distribusi Frekuensi Masa Kerja

\begin{tabular}{cccc}
\hline No & Masa Kerja & Frekuensi & Persen \\
\hline 1 & $1-3$ tahun & 30 & $42,85 \%$ \\
\hline 2 & $4-6$ tahun & 30 & $42,85 \%$ \\
\hline 3 & $7-9$ tahun & 10 & $14,2 \%$ \\
\hline & Jumlah & 70 & $100 \%$ \\
\hline
\end{tabular}

Rata-rata responden telah bekerja sebagai karyawan bagian produksi Laundry selama 6 tahun. Penelitian dengan responden pekerja perempuan menunjukkan perbedaan kemampuan berkeringat (sweating sensitivity) berdasarkan masa kerja. Pekerja dengan masa kerja di atas 5 tahun cenderung memiliki sweating rate yang lebih rendah dibanding kelompok dengan masa kerja baru. Kondisi ini disebabkan oleh fungsi adaptasi yang telah berjalan lebih baik. Meskipun telah terjadi adaptasi, namun tidak berarti sistem ekskresi ginjal tidak mengalami gangguan.

Berbagai studi menunjukkan bahwa dampak gangguan kerja ginjal dapat muncul pada pekerja dengan masa kerja di atas 5 tahun. Gangguan kerja ginjal yang kronis ini pada akhirnya dapat berdampak pada gagal ginjal. Lingkungan kerja dan kebiasaan responden dalam konsumsi cairan merupakan faktor yang berpengaruh besar pada gangguan fungsi ginjal.

Berat Jenis dan Osmolalitas Urin

Tabel 4. Distribusi Frekuensi Berat Jenis dan Osmolalitas Urin (Rerata per kelompok tiap pengambilan sampel)

\begin{tabular}{llccccccc}
\hline & BJ I & & Osmol I & & BJ II & \multicolumn{2}{c}{ Osmol } \\
& & & & & & II & \\
\hline A & B & A & B & A & B & A & B \\
\hline 1,0261 & 1,0264 & 1050 & 1050 & 1,0264 & 1,0264 & 1050 & 1050
\end{tabular}

Pada total penjumlahan data pengambilan sampel di 2 kelompok percobaan akan didapatkan rerata BJ 1,0258 (SD 0,0057). Sedang rerata osmolalitas adalah 893,50 (SD 212,48). Uji Mann-Whitney terhadap berat jenis urin dua kelompok pekerja didapatkan 
hasil U 608,00, dan $p$ value 0,954 yang berarti Ho diterima $(\rho>0,05)$ yaitu tidak ada perbedaan berat jenis urin antara 2 kelompok tercoba. Sedang hasil uji terhadap osmolalitas urin menunjukkan hasil $\mathrm{U}=611,00$, dan $p$ value 0,984 yang berarti Ho diterima $(\rho>0,05)$ yaitu tidak ada perbedaan pada rerata osmolalitas urin dua kelompok tercoba.

Berat jenis dan osmolalitas urin sangat tergantung pada cairan dan jumlah zat terlarut yang diproduksi oleh tubulus ginjal (Hardjasasmita P,2002: 156). Pemeriksaan berat jenis urin merupakan salah satu metode untuk menilai fungsi ginjal maupun hidrasi cairan seseorang terutama dalam kondisi suhu lingkungan yang tinggi (Brake and Bates, 2003). Untuk kepentingan praktis di lapangan pengukuran BJ urin dapat menilai kondisi euhydrated $(\mathrm{BJ}=1,015)$ maupun voluntary hypohydrated $(\mathrm{BJ}>1,025$ ) berdasar klasifikasi Australia Pathology Association (APA). Kehilangan cairan akibat kerja fisik maupun temperatur lingkungan sebanyak 1,5\% dari berat badan telah dapat berpengaruh pada performa fisik individu.

Dari hasil pemeriksaan laboratorium terhadap BJ urin 70 responden pekerja laundry didapatkan rerata 1,0258, sedangkan osmolalitas $893,5 \mathrm{mOsm} / \mathrm{Kg}$. Nilai BJ ini sesuai dengan kategori voluntary hypohydrated menurut klasifikasi APA. Kondisi ini dapat disebabkan konsumsi air minum yang kurang selama bekerja. Dari data awal pemeriksaan didapatkan 16 pekerja (47\%) memiliki BJ urin 1,030 yang sebaiknya harus dilakukan pemantauan terhadap kondisi fisik maupun asupan cairan. Dibanding indikator BJ, kadar osmolalitas urin lebih dipercaya untuk melihat kemampuan pemekatan ginjal karena relatif sedikit faktor yang mempengaruhi. Hasil pemeriksaan dengan konversi nilai BJ urin menunjukkan rerata osmolalitas yang masih berada pada rentang fisiologis (nilai normal 50-1400 mOsm/Kg). Rentang fisiologis ini menunjukkan bahwa tubuh masih mampu melakukan adaptasi terhadap pembentukan urin dalam keadaan suhu lingkungan tinggi.

Tidak adanya perbedaan dalam rerata hasil dua kelompok ini dapat disebabkan dari jumlah cairan yang diminum pekerja masih belum memenuhi kebutuhan metabolisme tubuh dalam suhu tinggi . Penambahan elektrolit $(\mathrm{Na}, \mathrm{K})$ dalam cairan tanpa diimbangi volume yang cukup tidak akan mampu memperbaiki nilai BJ maupun osmolalitas akibat volume urin yang lebih kecil dibanding kadar zat terlarut sehingga menghasilkan urin yang pekat. Pemberian elektrolit sesaat lebih diharapkan pada perbaikan keseimbangan elektrolit cairan tubuh. Pemberian elektrolit yang tepat diharapkan dapat mencegah heat cramps maupun heat exhaustion. Perbaikan BJ urin dapat tercapai apabila konsumsi cairan perjam mencapai 1,4-1,8 liter pada kondisi yang ekstrem seperti pekerja tambang bawah tanah maupun personil militer di gurun pasir.

\section{KESIMPULAN}

Rerata BJ urin tergolong tinggi dan masuk dalam kategori moderately hypohydrated. Kondisi ini disebabkan karena volume cairan elektrolit yang diminum belum mencapai kebutuhan penggantian yang dipersyaratkan. Nilai osmolalitas masih termasuk dalam kategori normal. Hal ini akibat adanya adaptasi pada suhu tinggi dan ginjal masih 
dapat melakukan kompensasi fungsi pemekatan urin. Perusahaan dapat melakukan edukasi pada pekerja untuk menambah konsumsi air minum dengan elektrolit hingga mencapai 1,5-2 liter selama 4 jam. Juga dapat dilakukan pemeriksaan BJ urin dan osmolalitas setiap 3 bulan secara berkala. Air minum diharapkan dapat diletakkan lebih mendekati ruang kerja.

\section{DAFTAR PUSTAKA}

Armstrong, H. S., Hacker et al. (2008). Urinary Indices During Dehydration, Exercise And Rehydration. International Journal Sport Nutrition. 8, 345-55.

Avellini , K., Krajewski JT (2009). Physiological Responses Of Physically Fit Men And Women to Acclimatization to Humid Heat. Journal of Applied Physics. 49, 254-61.

Brake, and Bates (2003). Fluid Losses and Hydration Status of Industrial Workers Under Thermal Stress Working on Extended Shifts. Occupational and Environmental Medicine (serial online): 60.

Donoghue et al. (2010). Heat exhaustion in a Deep Underground Metalliferrous Mine. Occupational and Environmental Medicine (serial online), 57.

Drinkwater, B., Loucks AB .(2002). Sweating Sensitivity and Capacity of Women in Relation to Age. Journal of Applied Physics. 44, 567- 578.

Epstein , Y S and Brill. (2003), Role Of Surface Area- To- Mass Ratio and Work Efficiency in Heat Tolerance. Journal of Applied Physics. 54, 831-836.

Greenleaf et al. (2008). Drinking and Water Balance During Exercise and Heat Acclimation. Journal of Applied Physics. 54, 414-419.

Greenleaf , C. BL. (2011). Exercise Temperature Regulation in Man during Hypohydration and Hyperhydration. Journal of Applied Physics. 30, 847-53.

Gleeson. (2014). Fluid Requirements for Exercise. Sports Nutrition Journal.

Karina, SM. (2012). Tekanan Panas pada Pekerja Pabrik Billet Baja PT. Krakatau Steel Cilegon Jawa Barat Tahun 2009. In Proceeding Konas Persagi. Jakarta.

Mack, N. ER. (2006). Body Fluid Balance during Heat Stress in Humans. In: Fregly MJ, Blatteis CM, eds. Handbook of Physiology. Section 4, Environmental Physiology, 1. Oxford: Oxford University Press.

Melin B, J. C., Savourey G, et al (2007). Effects of Hydration State on Hormonal and Renal Responses during Moderate Exercise in the Heat. Abstract. Journal of Applied Physics. 76, 320-327

Montain , S. MN, and Wenger CB. (2001). Hyponatremia Associated with Exercise: Risk Factors and Pathogenesis. Exerc Sport Sci Rev. 29: pp 113-7.

Morimoto T., Slabochova. Z., Naman RK., and Sargent F. (2007). Sex Differences in Physiological Reactions to Thermal Stress. Journal of Applied Physics. 22, 526-32.

Nose H et al .(2008). Shift in Body Fluid Compartments after Dehydration in Humans. Abstract. Journal of Applied Physics. 65, 318-324.

Parsons KC. (2009). International Standards for The Assessment of The Risk of Thermal Strain on Clothed Workers In Hot Environments. Annals of Occupational Hygiene. 43, 297-308. 
Rivera, AM et al. (2009). Drink Composition, Voluntary Drinking and Fluid Balance In Exercising, Trained, Heat Acclimatized Boys. Journal of Applied Physics. 86, 78-84.

Sanders MS. Mc Cormick EJ. (2007). Atmospheric Conditions. In: Human Factors In Engineering And Design. Mc Graw - Hill Book Company. New York, 273-285.

Sawka, W. CB., Pandolf KB. (2006). Thermoregulatory Responses to Acute ExerciseHeat Stress and Heat Acclimation. In: Fregly MJ, Blatteis CM, eds. Handbook of Physiology. Section 4. Volume 1. Environmental Physiology. New York: Oxford University Press, 157-185.

Schutte PC., Zenz C. (2004). Physical Work and Heat Stress. In: Zenz C, Dickerson OB, Horvath EP. Occupational Medicine, 3rd Edition. St Louis: Mosby.

Vrijens DMJ and Rehrer NJ. (2009), Sodium Free Fluid Ingestion Decreases Plasma Sodium during Exercise in The Heat. Journal of Applied Physics. 86, 1847-1851.

Williams. (2005). Human Energy. In : Nutrition for Fitness and Sport. 90-93. Fourth Edition. Brown and Benchmark. Chicago. 